\title{
Inner and Outer Horizons of Time Experience
}

\author{
Jiří Wackermann \\ Institute for Frontier Areas of Psychology and Mental Health, Freiburg i.Br., Germany
}

\begin{abstract}
Human experience of temporal durations exhibits a multi-regional structure, with more or less distinct boundaries, or horizons, on the scale of physical duration. The inner horizons are imposed by perceptual thresholds for simultaneity $(\approx 3 \mathrm{~ms})$ and temporal order $(\approx 30 \mathrm{~ms})$, and are determined by the dynamical properties of the neural substrate integrating sensory information. Related to the inner horizon of experienced time are perceptual or cognitive "moments." Comparative data on autokinetic times suggest that these moments may be relatively invariant $\left(\approx 10^{2} \mathrm{~ms}\right)$ across a wide range of species. Extension of the "sensible present" $(\approx 3 \mathrm{~s})$ defines an intermediate horizon, beyond which the generic experience of duration develops. The domain of immediate duration experience is delimited by the ultimate outer horizon at about $\approx 10^{2} \mathrm{~s}$, as evidenced by analysis of duration reproduction experiments (reproducibility horizon), probably determined by relaxation times of "neural accumulators." Beyond these phenomenal horizons, time is merely cognitively (re)constructed, not actually experienced or "perceived," a fact that is frequently ignored by contemporary time perception research. The nyocentric organization of time experience shows an interesting analogy with the egocentric organization of space, suggesting that structures of subjective space and time are derived from active motion as a common experiential basis.
\end{abstract}

Keywords: autokinetic time, dual klepsydra model, duration reproduction, phenomenal horizon, psychophysics, subjective time, temporal experience

La experiencia humana de las duraciones temporales exhibe una estructura multi-regional, con fronteras, u horizontes, más o menos definidos, en la escala de la duración física. Los umbrales perceptivos de la simultaneidad $(\approx 3 \mathrm{~ms})$ y el orden temporal $(\approx 30 \mathrm{~ms})$ imponen los horizontes internos y los determinan las propiedades dinámicas del substrato neuronal que integra la información sensorial. Los "momentos" preceptuales o cognitivos se relacionan con el horizonte interno del tiempo experimentado. Los datos comparativos sobre tiempos autoquinéticos sugieren que estos momentos pueden ser relativamente invariantes $\left(\approx 10^{2} \mathrm{~ms}\right)$ a través de una amplia variedad de especies. La extensión del "presente sensible" $(\approx 3 \mathrm{~s})$ define un horizonte intermedio, a partir del cual se desarrolla la experiencia genérica de la duración. El dominio de experiencia de duración inmediata es delimitado por el último horizonte externo en aproximadamente $\approx 10^{2} \mathrm{~s}$, como demuestra el análisis de los experimentos de la reproducción de la duración (la reproducibilidad del horizonte), probablemente determinado por los tiempos de relajación de los "acumuladores neuronales." Más allá de estos horizontes fenomenológicos, el tiempo meramente se (re)construye cognitivamente, no es experimentado ni "percibido", un hecho que a menudo es ignorado por la investigación contemporánea de la percepción del tiempo. La organización niocéntrica de la experiencia del tiempo muestra una interesante analogía con la organización egocéntrica del espacio, sugiriendo que las estructuras de espacio y tiempo subjetivos se derivan del movimiento activo como una base experimental común. Palabras clave: tiempo autoquinético, modelo dual klepsidra, reproducción de la duración, horizonte fenomenológico, psicofísica, tiempo subjetivo, experiencia temporal

The author wishes to thank Werner Ehm for turning our attention to Riemann's philosophical writings, Erki Tammiksaar for kindly providing a copy of von Baer's lectures, and David Robinson for his helpful comments and criticism on an earlier draft of the present paper.

Correspondence concerning this article should be addressed to Jiri Wackermann. Abtl. Empirische und Analytische Psychophysik, Institut für Grenzgebiete der Psychologie und Psychohygiene, Wilhelmstrasse 3a, D-79098 Freiburg i.Br. (Germany). Phone: +49 761 2072171. Fax: +49 761 2072179. E-mail: jw@igpp.de 


\section{Introduction}

"We are confounded and perplexed about time," wrote George Berkeley (1730/1996) in a letter to his friend Samuel Johnson. During the following centuries, discussions and speculations on the nature of time demonstrated the truth of Berkeley's words. Time has often been called a "problem," even a "mystery" (Nichols, 1891) or an "enigma" (Boslough, 1990). It seems, however, that most aspects of the so-called "problem of time" originate from the incongruence between the concept of time as a measurable continuum as used in science and technology, and the experience of temporal order and temporal relations as immediately given to our consciousness.

\section{Perceptual Horizons}

The present paper $^{1}$ focuses on the multi-regional structure of the experience of time, and on the experimental evidence for the "horizons" separating these regions. The term horizon is borrowed from phenomenological philosophy, especially from the late Edmund Husserl (1937/1976) and his analyses of the structure of the pre-scientific "life-world" (Lebenswelt). Briefly, "horizons [are] not merely open areas of decreasing clarity, but parts of the comprehensive horizon of a world as their encompassing frame of reference, without which any account of even a single perception would be incomplete." (Spiegelberg, 1994, p. 146).

In our usage, "horizon" signifies a boundary defining a region with a certain experiential characteristic. The metaphoric origin of the notion is obvious: Referring to the visual experience of the world, "horizon" denotes the boundary separating the spatial region accessible to direct visual perception from the space "beyond." Beyond the horizon, there is space containing objects merely known to be there, accessible to cognitive reconstruction and symbolic representation (e.g., by a map), but never actually seen: with a change of the observer's position, some objects enter the visual field while others disappear beyond the horizon. A somewhat paradoxical fact about the visual horizon, revealed by phenomenological analysis, is that the horizon itself is both seen and is not seen. It is seen insofar as it is an identifiable element of the visual experience-but we cannot say that we really see the horizon in the same sense as we see all other things within the horizon. We can at best say that the visual horizon is an asymptotic boundary of visual experience.

In the field within the given horizon we may differentiate embedded regions of varying distinctness of perception, reflecting the well-known ego-centric organization of subjective space. With decreasing physical distance from the observer's body, the structure of experienced space becomes increasingly complicated; for example, at spatial locations closer to the visual organ than punctus proximus, the correlation between haptic and optic experience becomes blurred and finally lost. Then the ultimate boundary of possible visual experience is the surface of the visual organ itself, the eye. The eye is never seen by itself; ${ }^{2}$ its central role in visual perception is indicated only indirectly, from an allocentric perspective. The eye's location in space sets an impenetrable internal horizon on our visual experience.

\section{Physical versus "Psychological” Time}

From these preliminary remarks on the structure of experienced space, we proceed to that of experienced time. What is its relation to the dimension of time in physics? Time in physics is an instrumental prescription, constructing a map of an ordered series of events onto the continuum of real numbers, $A \rightarrow t_{A}, B \rightarrow t_{B}$, etc. Physical duration is the measure of time elapsed between two events $A$ and $B$, $d_{A B}=\left|t_{B}-t_{A}\right|$, which can be any non-negative number. Local simultaneity ${ }^{3}$ of events is equivalent to the statement that their time instants are identical, that is, $d_{A B}=0$. All this seems self-evident; however, the apparent evidence makes us easily forget that this is not an empirical fact but rather an a priori condition ${ }^{4}$ for a construction of "physical time" as a continuum. This abstract construct provides a useful concept-for example, we can apply arithmetic operations on time indices-but it does not reflect the intrinsic structure of experienced time. As shown in the

\footnotetext{
1 Part of this material was presented at the conference Towards a Science of Consciousness, Copenhagen, Denmark, August 17-20, 2005.

2 As noted by L. Wittgenstein in his Tractatus: "[D]as Auge siehst du wirklich nicht. Und nichts am Gesichtsfeld läßt darauf schließen, daß es von einem Auge gesehen wird." (Wittgenstein, 1918/1984, §5.633). - "You really do not see the eye. And nothing in the visual field allows you to infer that it is seen by an eye." - This phenomenological observation serves Wittgenstein as a metaphor for his notion of the metaphysical subject as an ultimate boundary of the experienced world: "die Grenze - nicht ein Teil - der Welt" (op.cit., §5.641). In the following we shall see that this applies to time as well: We will arrive at a boundary where the worldly notions of temporal order and durations lose their sense.

3 Here, "local" means that distinct events occur within a unitary field of perception so that spatial distances do not play any role.

4 For Kant (1787/1998), time (as well as space) is primarily not a concept but rather a form of intuition (Anschauung), a necessary prerequisite of organization of perceptions. From this point of view, the expression "experience of time" is logically deficient and rather misleading. In a vein similar to the Kantian thought, we could well say that the concept of time in physics is not an observable but rather a form of organization of physical observations. Our usage of the expression "a priori" thus refers to the axiomatic basis of physics, not to the "a priori" of primary intuition.
} 
forthcoming sections, studies in perception and judgment of temporal relations reveal regions of qualitatively different temporal experience, bounded by more or less distinct horizons; in particular, experienced time has no "null point" equivalent to zero physical duration.

These observations, however, should not be interpreted in a straightforward manner as empirically determined properties of a different, non-physical entity. Some authors (e.g., Cohen, 1964; Lehmann, 1967; and others) held the view that "psychological time" is something essentially different from "physical time," thus suggesting a sort of substance dualism. However, this proposal did not contribute anything positive to our understanding of human experience of time; it only polluted the universe of discourse with new, mysterious entities. A pragmatic approach, combining phenomenological and psychophysical methods, may be more promising and productive (cf. Wackermann, 2005). In particular, such interdisciplinary studies should shed light on the constitution of the "objective" time out of the temporal aspect of "subjective" experience.

\section{Inner Horizons of Temporal Experience}

The concept of the horizon as the "boundary defining a region of a certain experiential characteristic" (Section 1.1) shows some similarity with the concept of threshold commonly used in sensory physiology and psychophysics. ${ }^{5}$ Determination of thresholds, that is, minimal durations required for a certain temporal experience to occur, may thus provide experimental evidence for horizons of temporal experience.

\section{Thresholds of Simultaneity and Temporal Order}

Temporal experience is primarily experience of succession. The relations of temporal order between events, " $A$ occurs before $B$," or " $A$ occurs after $B$," constitute the most elementary form of temporal judgment, preceding a metrical concept of time scale. Our notion of time as a perfectly ordered universe of events implies that any two events, $A$ and $B$, are comparable as to their temporal order. If $A$ occurs neither before $B$ nor after $B$, then the events $A$ and $B$ are simultaneous. These axiomatic foundations are a matter of logic; only physical conditions of experience of simultaneity or temporal order are subject to empirical research.

Experimental data shows that two stimuli have to be separated by a minimum time interval to be perceived as non-simultaneous; this fusion threshold is about $\approx 3 \mathrm{~ms}$ for acoustic stimuli, $\approx 10 \mathrm{~ms}$ for visual and tactile stimuli. However, a time interval of $\approx 20-40 \mathrm{~ms}$ between the two stimuli is required to indicate their relative order; this order threshold is reportedly independent of sensory modality (Pöppel, 1978, 1997). The existence of two distinct thresholds for two different aspects of temporal discrimination is usually interpreted as evidence for multiple brain mechanisms being involved: one responsible for the integration of a unitary percept, another for determination of succession between different percepts.

In the logical scheme sketched above, for any two events that are not simultaneous, one must occur either before or after the other, that is, their order is determined. Interestingly, this is not the case in human perception; two stimuli separated by a time longer than the fusion threshold but shorter than the order threshold produce two distinct perceptual events, order of which, however, is not uniquely determined. Concerning this relative indeterminacy, Atmanspacher and Filk (2003) proposed an explanative approach based on generalized quantum theory, a "temporal double-slit scenario" in which discrimination and sequentialization of events are considered as complementary (non-commuting) observables.

Taking abstraction from neurobiological or neurophysical interpretations, and focusing on the phenomenological characteristics, we may denote the thresholds of simultaneity and sequential order as the first and second inner horizons of temporal experience. As is typical for perceptual horizons, counter-intuitive or puzzling illusory phenomena can be observed in the vicinity of these inner horizons. The "temporal displacement" (Zeitverschiebung), described first by Wundt, belongs to this category. Vicario (2003) described temporal displacement in perception of tonal sequences (inversion of high/low tones) occurring at a tone duration of $160 \mathrm{~ms}$ - that is, far away from the order threshold for elementary stimuli. Recently, Morrone, Ross, and Burr (2005) reported inversion of temporal order between two events separated by $100 \mathrm{~ms}$, if the pair of events preceded a saccadic eye movement by a period of -70 to $-30 \mathrm{~ms}$.

All these findings indicate how vulnerable, fragile, and prone to disintegration temporal experience is in perihorizontal regions (sub-second domain). The spectacular phenomena of order indeterminacy or order reversal may be interesting, and their interpretations may entrain new insights into the brain's functioning. However, it is questionable how much or little their study contributes to our understanding of real-life temporal experience.

\footnotetext{
5 The apparent similarity should not obscure the essential difference: Thresholds are conceived as properties of the biological or psychophysical systems under study; horizons are features of the perceptual situations in their entirety. Moreover, thresholds are usually determined directly, varying a physical property of the stimulus on a one-dimensional continuum, whereas horizons may be given indirectly, as limiting values or singularities in a multi-dimensional variety of physical characteristics of the perceptual situation.
} 


\section{"Perceptual Moments" and the Question of Internal Time Scales}

What is the duration of an elementary perception, that is to say, of a perceptual event corresponding to a pointlike physical event? This problem has a long tradition in sensory physiology and experimental psychology. For example, Fröhlich (1923) described the flash lag phenomenon and estimated from its magnitude the duration of elementary visual sensation (Empfindungszeit) to be 40-150 ms. Efron (1972) estimated the minimal perceptual duration to be about 150-160 ms. The importance of these findings with respect to understanding central mechanisms of temporal experience is problematic. Thus Patterson criticized the concept of perceptual moment, and pointed out that studies by Allport, Efron and Lee, etc. "are not relevant to these models [of perceptual moment] because the studies involved the investigation of peripheral, sensory mechanisms whereas the models propose the operation of a central intermittency" (Patterson, 1990).

Proceeding from peripheral sensory subsystems to central representation and processing of sensory information, we may rephrase the question of perceptual moments to that of "mental tempo." More generally and in line with the cognitivist façon de parler, the problem concerns characteristic time scales of internal information processing, and their relation to temporal experience. This problem has provoked speculative thoughts throughout the course of many centuries.

It was again Berkeley who raised the question, "What if succession of ideas were swifter, what if slower?" (Berkeley 1707/1996, §B16), implying that the tempo of succession of mental contents determines the time base of experience. This followed from Berkeley's principal tenet that "nothing but ideas [are] perceivable" (op. cit., §B50), backed up by the observation that "in some dreams succession of ideas is swifter than at other times" (op. cit., §B39).

In a similar vein, von Baer $(1864)^{6}$ held that "there is no doubt that a human being can measure nature only with herself, in terms of space as well as of time" (p. 267), and he even extrapolated this idea to the entire realm of animated beings: "the inner life of a human or of an animal can during the same external time [period] pass faster or slower, and this inner life is the standard with which we measure time when we observe [processes in] Nature." (op. cit., pp. 257$258)^{7}$

We find thoughts of a similar sort in the philosophical writings of Bernhard Riemann: ${ }^{8}$

It seems that different thought processes differ mainly with respect to their temporal rhythm. If plants are animated [beings], then hours and days must be for them what seconds are for us; the corresponding time interval for the soul of the Earth, at least for its external activity, embraces perhaps many thousands of years (Riemann, 1953/1958, p. 518).

In the modern literature, the problem of the time scale of cognitive processes is usually set in the context of a hypothetically discrete structure of mental activity, or "psychological time" as such (e.g., Geissler, 1987; Shallice, 1964; Stroud, 1954). For example, Pöppel (1978, p. 715) hypothesized "central temporal processing units or subjective time quanta with a duration in the range 20-40 ms." Closely related is the hypothesis of an oscillatory basis of organismic time (e.g., Dehaene, 1993; Pöppel, 1972; Treisman, 1963), known under the suggestive title of "internal clock;" the period of the clock determines the duration of an elementary time quantum. ${ }^{9}$ Arguments supporting these hypotheses are usually derived from experiments similar to those proposed for the determination of perceptual moments. Experimental neurophysiology may also provide supportive data. For example, spatial analysis of the time series of brain electrical fields reveals a discrete structure in the brain's activity consisting of a temporal sequence of so-called "micro-states" (Lehmann, Ozaki, \& Pal, 1987); the durations of these microstates are of the order of magnitude $\approx 100 \mathrm{~ms}$. It has been hypothesized that the micro-states represent elementary steps of information processing, the "building blocks of consciousness" or, metaphorically, the "atoms of thought" (Lehmann, 1990).

6 K.E. von Baer (1792-1846), German-Estonian biologist, renowned for his work in embryology (discovery of egg-cell in vertebrates) and developmental biology, a "forerunner and critic of the theory of natural selection" (Kull, 1999).

7 In German original: “[D]as innere Leben eines Menschen oder Thiers [kann] in derselben äußern Zeit rascher oder langsamer verlaufen, und dieses innere Leben ist das Grundmaaß, mit welchem wir bei Beobachtung der Natur die Zeit messen.”

8 G.F.B. Riemann (1826-1866), German mathematician. Quoted text in German original: "Die verschiedenen Denkprocesse scheinen sich hauptsächlich zu unterscheiden durch ihren zeitlichen Rhythmus. Wenn die Pflanzen beseelt sind, so müssen Stunden und Tage für sie sein, was für uns Secunden sind; der entsprechende Zeitraum für die Erdseele, wenigstens für ihre Thätigkeit nach aussen, umfasst vielleicht viele Jahrtausende."

9 The "internal clock model" and related theories (cf. Grondin, 2001) present a complex of problems that cannot be treated adequately in the present paper. For a criticism of the technomorphic concept of the "internal clock", see Wackermann and Ehm (2006), also Wackermann (2005), p. 196. 


\section{Autokinetic Invariance}

Speculations about the time scale of inner experience of infra-human species are beyond the limits of experimental verification. However, biology's observational data may provide some information about time scales of interactions between organisms and their physical environments.

The bodily size of an organism determines a natural "length unit" of its "action-world," or Umwelt, as defined by von Uexküll (1928). This is to say, the typical body size determines the scale of spatial extensions of relevant objects, and distances to those objects. We will call the ratio $\tau=l / v$, that is, the time required to traverse the organism's own body length $l$ at its maximal locomotion speed $v$, "autokinetic time." 10 It is reasonable to assume that intra-organismic information processing, from sensory input to motor output, must proceed at rates comparable with the rate of change in the organism's perception/action field induced by the organism's active motion. Hence the autokinetic time $\tau$ may provide a rough estimate of the time scale of intra-organismic information processing. Figure 1 shows length-velocity data for 29 different animal species, plotted in log-log coordinates: The autokinetic times $\tau$ are confined to a narrow range between 30 to $300 \mathrm{~ms}$, with the geometric mean $\approx 100 \mathrm{~ms}$. This relative ${ }^{11}$ invariance indicates that elementary information processing times are universally in the order of magnitude of $10^{-1} \mathrm{~s}$; a value which is, interestingly, in agreement with estimates of "perceptual moments" or "brain functional microstates" quoted in the preceding section.

Of course, the autokinetic invariance is not to be interpreted as a manifestation of harmonie préétablie between species. It is merely one of many allometric relations known in comparative biology (Charnov, 1993), and should be interpretable on a basis of biophysics, in terms of intra-organismic energy production, its translation to kinetic energy via motor effectors, etc. It is nonetheless important that autokinetic times can be specified for behaving organisms solely on the basis of observational data, independently of our attributing "consciousness" or "subjective experience" to the species (cf. Baars, 2005; Griffin \& Speck, 2004), and interpreted as characteristic times of information processing.

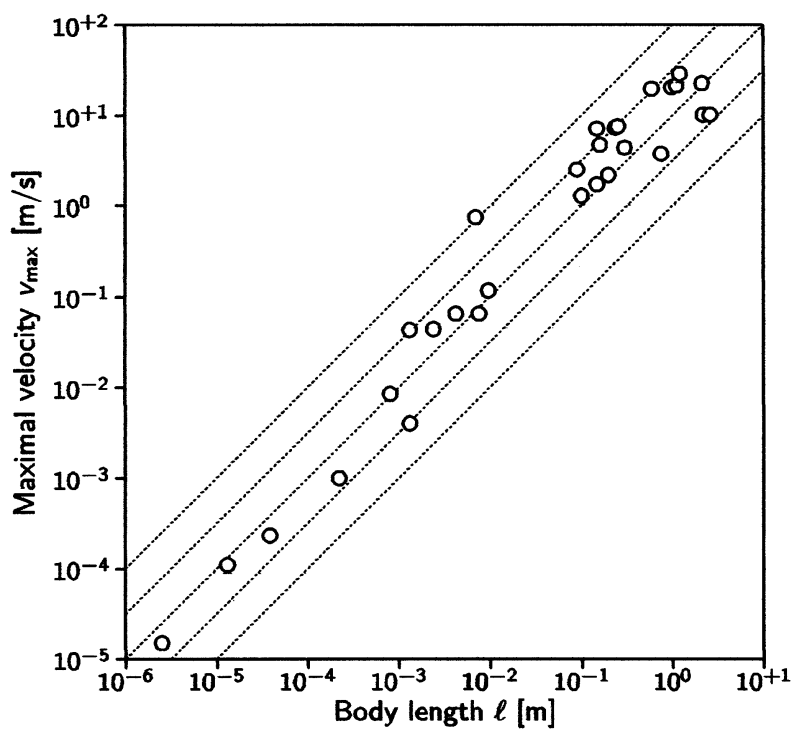

Figure 1. Maximal locomotion velocity, $v_{\max }$, plotted vs. body length, $l$, for a variety of 29 animal species (open circles; data from McMahon \& Bonner, 1983). The dashed diagonal line indicates autokinetic time $\tau=l / v=100 \mathrm{~ms}$; the parallel dotted lines indicate times $\tau$ from 10 to $1000 \mathrm{~ms}$, with step factor $\sqrt{ } 10 \approx 3.162$. Most data points are concentrated within a narrow band from $\approx 30$ to $\approx 300 \mathrm{~ms}$.

\section{Outer Horizons of Temporal Experience}

\section{The "Sensible Present"}

The notion of the sensible present ${ }^{12}$ was coined by William James to express the fact that the present "now" is not a dimensionless point in time but seems to have a certain extension: "[t]he knowledge of some other part of the stream [of consciousness], past or future, near or remote, is always mixed in with our knowledge of the present thing" (James, 1890, p. 606). In a succession of events, the contents of the present awareness is a subset of immediately past events, as "objects fade out of consciousness slowly" (op. cit., p. 607). In a well-known Jamesian metaphor, "the practically cognized present is no knife-edge, but a saddle-back, with a certain breadth of its own on which we sit perched, and from which we look in two directions into time" (op. cit., p. 609).

\footnotetext{
10 From the Greek $\alpha v \tau \mathrm{o}=$ self, $\kappa \iota v \eta \sigma ı \varsigma$ = motion; this term has no relation to "autokinetic illusions" (Adams, 1912) in visual perception.

11 The qualifier "relative" should be understood in terms of the orders of magnitude: The ratios $\tau$ are concentrated in the range $10^{-1 \pm 1 / 2} \mathrm{~s}$, that is, in a zone of width 1:10, while the lengths and velocities cover a range of about 1:106.

12 Also referred to as "specious present," a term which James in fact had borrowed from E.R. Clay. Other authors also used different terms, such as "subjective present," "presence time," etc. (cf. Pöppel, 1978, p. 723, and references therein).
} 
Referring to experimental results of Wundt and collaborators, James estimated duration of the sensible present to be from 3 to $12 \mathrm{~s}$ : "[t]he specious present has [...] a vaguely vanishing backward and forward fringe; but its nucleus is probably the dozen seconds or less that have just elapsed" (op. cit., p. 613). The elements leaving and entering the present awareness were considered by James as "the germs of memory and expectation," or plainly "the retrospective and the prospective sense of time" (op. cit., p. $606)$, a concept reminding of retention and protention revealed by Husserl's (1928/2000) phenomenological analyses of time consciousness. ${ }^{13}$

James' concept of the sensible present has been generally accepted. Contemporary research into time perception and timing behavior has surprisingly little to add to it, except of an updated terminology and an extended experimental database. In the modern information-processing parlance, the sensible present is usually interpreted as a result of the temporal integration of information (Pöppel, 1978, 2004; von Steinbüchel, Wittmann, \& Szelag, 1999). Experimental methods used to determine the temporal extension of the "integration window" include, for example, grouping of beat trains into perceptible units, or perception of ambiguous/multi-stable visual or acoustic stimuli. The reported results satisfactorily converge in the range from 2 to $3 \mathrm{~s}$. Also, auxiliary data from areas as diverse as neuropsychology, neurolinguistics, and cultural anthropology are being reported to corroborate the special status of the 2-3 s range (Pöppel, 2004, p. 299; von Steinbüchel et al., 1999, p. 175).

The experience of temporal order is preserved within the sensible present, but requires active attention: "to sensible perception, its elements are inseparable, although attention looking back may easily decompose the experience, and distinguish its beginning from its end" (James, 1890, p. 610). Exceeding the critical duration of $\approx 3 \mathrm{~s}$ causes an erosion and disintegration of perceived unity in time. Discrete sensory events or motor actions separated by shorter intervals can be easily integrated to a unitary experience of rhythm; with increasing interval, the experience of emptiness occurs, perceivably separating one event or action from the subsequent one, and thus imposing a definite temporal order on them.
Seen "from the other side" (i.e., that of established temporal order), the sensible present occurs as a "melting zone" in the progression of time: "although we are aware of successiveness, we cannot give the items in a reliable order" (Dobbs, 1972). The boundary of the sensible present thus occurs as a relative or intermediate horizon, the meaning of which depends on whether we approach the horizon from within or from without. Only by transgressing this horizon do we enter the domain of perceivable duration in the proper sense of the word.

\section{Time Reproduction and the Dual-Klepsydra Model}

An interesting aspect of duration experience is revealed by experiments with reproduction of temporal durations. In a typical time reproduction task (TRT), the participant is presented a sensorily perceivable (e.g., visual) stimulus of duration $s$, controlled by the experimenter. After an interstimulus interval (ISI), $w$, the stimulus is presented again, and the participant's task is to indicate (e.g., by a pressing a response key) the moment at which the duration of the latter stimulus is equal to the duration of the former stimulus. The TRT is one of the classical methods of the experimental psychology of time (Eisler, 2003; Richards, 1964; Vierordt, 1868; Woodrow, 1930), and reportedly produces smaller error variance than other methods, that is, duration production or magnitude estimation (Bindra \& Waksberg, 1956).

It is, however, not quite clear what the reproduction method really measures. The mean reproduced durations, $r$, plotted as a function of the stimulus duration, $s$, show typically (a) under-production with respect to the chronometrically correct response, $r=s$, and (b) a non-linear course with a negative curvature, indicating progressive shortening of the response with respect to the stimulus $s$ (Figure 3; Wackermann, Späti, \& Ehm, 2005). The standard "internal clock model" with a constant pacemaker frequency does not easily account for this phenomenon. Eisler's (1975) "parallel clock model," devised specifically for duration reproduction, does account for the non-linear course of the reproduction response but only by piecewise linear approximation.

\footnotetext{
13 How much, if anything, Husserl owes to James is a question beyond the scope of the present paper. The important contribution of both authors was the discovery of the co-presence of past (and to some extent, future) in the present "now" as a constitutive element of subjective consciousness of time. Husserl's "diagram of experienced time" (Husserl, 1928, p. 23) shows a striking parallelism with the graphic representation of co-present past proposed by Ward and mentioned by James on p. 629. What Husserl denotes as the "horizon of the past" (Vergangenheitshorizont) occurs in James' account as "a sort of perspective projection of past objects upon present consciousness" (op. cit., p. 630). - However, we should not overlook the novel moment of Husserl's phenomenology, which was radically innovative in searching for apodictic evidence solely in pure phenomena, without referring to results of positive sciences (psychology). The contemporary trend to merge phenomenology with natural sciences (Varela, 1999) would appear from the radical Husserlian perspective as a rather suspect and counter-productive move.
} 
(a)

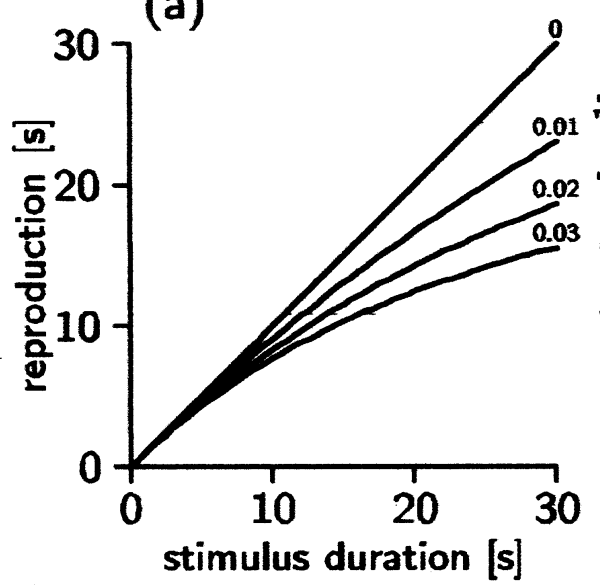

(b)

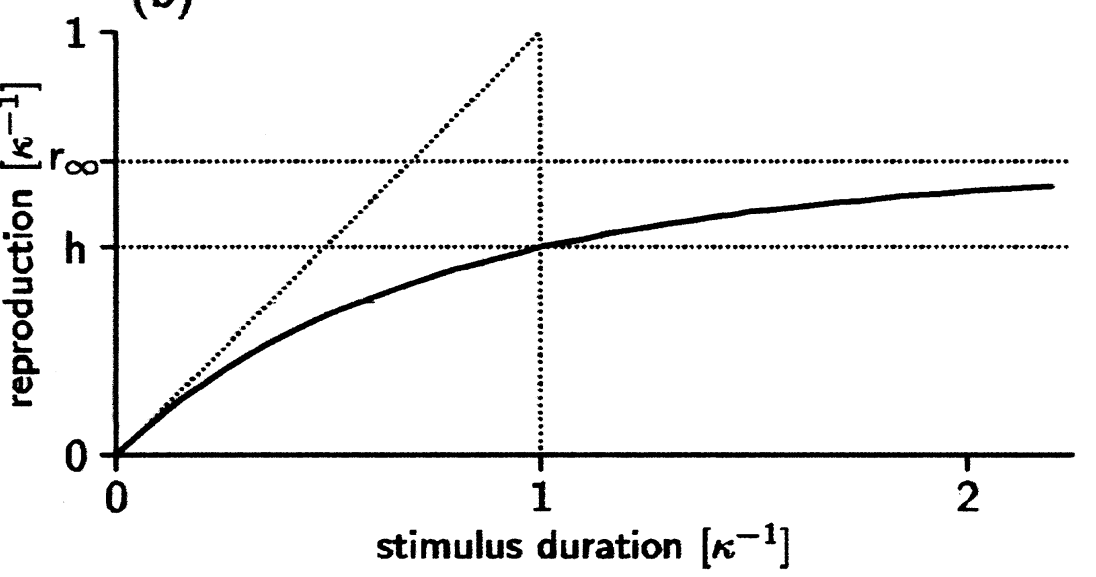

Figure 2. Theoretical response curves (TRC) predicted by the dual-klepsydra model (DKM) of duration reproduction. — Left (a): TRCs for varied values of parameters $\kappa=0,0.01,0.02,0.03 \mathrm{~s}^{-1} ;(\eta=1, w=0$ for all curves). Right (b): "Anatomy" of the TRC ( $\eta=1, w=$ $0)$. Both axes labeled in $\kappa^{-1}$ units: $r_{\infty} \approx 0.7 \kappa^{-1}=$ asymptotic upper bound of response times; $h=\operatorname{krf}\left(\kappa^{-1}, 0\right) \approx 0.5 \kappa^{-1}$. The latter can be used for a rough estimate of $\kappa=(\text { stimulus duration } s \text { for which } r=s / 2)^{-1}$; for more precise methods to estimate KRF parameters see Wackermann and Ehm (2005, App. C).

The progressive shortening of reproduction responses is predicted by the dual-klepsydra model (DKM), which is based on two linear inflow/outflow systems ("leaky accumulators" or "klepsydrae"; Wackermann \& Ehm, 2006; Wackermann, Ehm, \& Späti, 2003). The model yields a socalled "klepsydraic reproduction function" (KRF),

$$
\operatorname{krf}(s, w)=\kappa^{-1} \ln \left(1+\eta\left(1-\mathrm{e}^{-\kappa s}\right) \mathrm{e}^{-\kappa w}\right),
$$

where $s=$ the original stimulus duration, $w=$ interstimulus interval, parameter $\kappa$ stands for the leakage rate of both accumulators, and $\eta=i_{1} / i_{2}$ is the ratio of inflows to the $1^{\text {st }}$ and $2^{\text {nd }}$ accumulator. (In most experimental situations, we assume $\eta=1$.) A detailed discussion of the DKM, including its extension to a stochastic model accounting for intraindividual response variance, has been given by Wackermann and Ehm (2006), while a possible neural implementation of the model is sketched in Wackermann (2005); see also Jech, Dušek, Wackermann, and Vymazal (2005) for results of a fMRI study supporting the assumption of the dual-accumulator structure.

\section{The Horizon of Reproducibility}

With a fixed ISI, $w=$ const, the KRF becomes a function of a single argument, $s$, specifying a theoretical response curve (TRC) that can be matched against experimental data. Generally, the TRCs are increasing functions of the stimulus duration, $s$, with a negative curvature (Fig. 2), except for $\kappa \rightarrow 0$, where the KRF becomes a linear function independent on the $\operatorname{ISI}, \operatorname{krf}(s, w)=\eta s$. The phenomenon of the progressive shortening of response times is thus explained by the model with constant flows, and without any additional assumptions or corrections. Figure 3 shows a KRF fitted to TRT data obtained with one individual participant in three experimental sessions, that yields an estimate of $\kappa=0.038$ $\mathrm{s}^{-1}$. For a model with only one degree of freedom ${ }^{14}$, this is a fairly good fit. Estimates of $\kappa$ from our experiments on the duration reproduction of visually presented stimuli are in the order of magnitude of $10^{-2} \mathrm{~s}^{-1}$ (Späti, 2005), which is in good agreement with estimates based on data reported by other authors (cf. Wackermann, 2005, p. 198). The inverse value, $\kappa^{-1}$, specifies the relaxation time of the klepsydrae, which is of the order of magnitude $10^{1}$ to $10^{2} \mathrm{~s}$.

The importance of $\kappa^{-1}$ as a natural "unit" on the scale of experienced duration manifests itself in the asymptotic properties of TRCs. For very long $s$, the KRF response is

$$
\lim _{s \rightarrow \infty} \operatorname{krf}(s, w)=\kappa^{-1} \ln \left(1+\mathrm{e}^{-\kappa w}\right) \leq r_{\infty}
$$

where the limiting value $r_{\infty} \equiv \kappa^{-1} \ln 2$ (see Figure 2). This is a surprising feature of the model; should we expect that a duration of, say, 1 hour, would be reproduced as 1 minute? Certainly not; but we should note that "reproduction" of such an extended duration does not rely on pure duration experience. It is virtually impossible to maintain the "carrier" of 1-hour duration in the focus of a subject's awareness;

14 This and all following estimates of parameter $\kappa$ were obtained with parameter $\eta$ fixed to unity. 


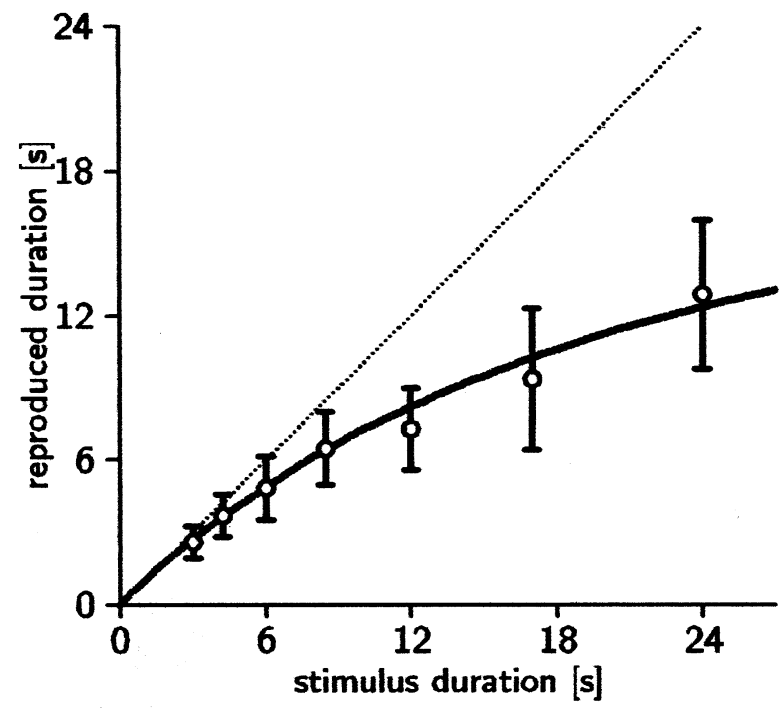

Figure 3. A typical response curve from a time reproduction experiment (data from Späti, 2005). The figure is based on aggregated data from three separate sessions with an individual participant (male, age 49 years), each session comprising 35 reproduction trials. Mean response times (open circles) \pm 1 SD (error bars) are shown as a function of stimulus duration, $s$, varied from 3 to $24 \mathrm{~s}$, with constant ISI $w=1.25 \mathrm{~s}$. The diagonal dotted line indicates the "chronometrically correct" response. The grey curve shows the theoretical response curve (TRC) fitted to the experimental data: $\kappa=0.038 \mathrm{~s}^{-1}$, which corresponds to relaxation time $\approx 26 \mathrm{~s}$.

other perceptual or internally generated events enter the field of attention and play the role of temporal cues (Pöppel, 1978). These cues create a frame of reference with respect to which the subject may cognitively reconstruct the duration ("it must have been about 1 hour"); similar processes may be involved in a reproduction of long durations.

A closer look at the form of the theoretical KRF (Figure 2) explains the necessity of the transition from the representation based presumably on continuous accumulation of neural excitation to another representation: With progressive flattening of the KRF, discrimination of durations in terms of their virtual reproduction becomes less and less reliable (Wackermann, 2005 , p. 201). We call this upper limit on durations accessible to live, immediate experience the "horizon of reproducibility." As is the case with other perceptual horizons, the horizon is never actually reached; its existence manifests itself in perception only indirectly. Based on the interpretation of duration reproduction experiments and their extrapolation, a plausible estimate of the position of the horizon on the physical time scale is $10^{2} \mathrm{~s}$, that is, roughly a few minutes.

\section{"Time Perceived" and "Time Known"}

The scope of reproductive memory for temporal durations thus appears as limited; that is to say, delimited by the outer horizon. This again was expressed by James who wrote:

Our maximum distinct intuition of duration hardly covers more than a dozen seconds, while our maximum vague intuition is probably not more than that of a minute or so. [...] The duration thus steadily perceived is hardly more than the "specious present" [...] Its content is in a constant flux, events dawning into its forward end as fast as they fade out of its rearward one (James, 1890, p. 630; italics his).

This description is not quite adequate as it depicts the sensible present as a sort of "pipeline," and ignores the increasing compression of the stream of events in the reproductive memory, blurring the temporal resolution of remote events. ${ }^{15}$ We have shown elsewhere (Wackermann $\&$ Ehm, 2006) that this progressive compression is explained by a so-called cumulative reproduction function, defined by means of the KRF (cf. also Wackermann, 2005, p. 201-202, for a revised version Husserl's diagram of experienced time, visualizing the effect of compression of the reproducible past). Importantly, James further observes that "the reproduction of an event, after it has once completely dropped out of the rearward end of the specious present, is an entirely different psychic fact from its direct perception in the specious present as a thing immediately past" (loc. cit.).

Metaphorically, we could say that the "pressure of the accumulated past" makes the fluid stream of events condense to a solid state, that is, a phenomenologically different mode. It is this "condensed" mode, in which past events are represented in the biographic memory, for example, as elements of narrative account. Representation of very long time intervals consists of a selection of a subset of discrete, isolated events upon which a relational structure is defined. We could say that very large temporal extensions are never really perceived, only known; the same applies to shorter durations between events in remote past. ${ }^{16}$

15 It seems that James does not distinguish clearly between (a) the de-blurring of perceivable order at the frontier of the "sensible present" period, and (b) the transformation of the perceived temporal order into a definitive order established by the relations known. In our view (a) and (b) are two qualitatively different phenomena; furthermore, we suggest that it is only within the region between horizons (a) and (b) that the experience of duration is fully developed.

16 I.M. Havel (2005) in his analyses of structure of experienced time emphasizes this discrete, network-like, relational structure, and postulates a discontinuous "granular" structure as an essential characteristic of subjective time ("stream of episodes"). Although we are greatly sympathetic to Havel's approach and we find numerous meeting points between his and our efforts, our approach is distinctly different: We are primarily interested in metricization of the region of perceivable durations by means of continuous functions, and we do not see any compelling reason to introduce discontinuity. 
Summarizing: the domain of "live experience" of temporal duration is a relatively narrow region, extending from the intermediate horizon of the sensible present (2-3 s) to the ultimate outer horizon, the horizon of actual reproducibility $\left(\approx 10^{2} \mathrm{~s}\right)$. Very short and very long physical durations are accessible only in a cognitive act but are not directly perceivable.

\section{Concluding remarks}

\section{Is there a Unitary Dimension of Subjective Time?}

The objective of this article is to draw attention to the notion of experiential horizon as a productive and indispensable concept for the understanding time experience. Of course, the phenomenal differences between different regions of physical durations have been known for a very long time. As one among many authors, Pöppel (1978) emphasized the need for a "taxonomy of 'elementary time experiences," and insisted that "time perception can be explained only if the different aspects of subjective time are first identified, before asking the question of how these relate to each other" (Pöppel, 1978, p. 726). ${ }^{17}$

However, if the modes of temporal experience corresponding to different regions, delimited by their respective horizons (Figure 4), are qualitatively different, the attempts to establish a unitary "psychology of time" are rather questionable. What have such disparate topics as perceptual moments, experienced duration, and time perspective, in common? Of course, speaking of the physical "correlates" of these phenomena, we have to refer in all cases to one and the same dimension of physical time. But this does not imply the necessity or plausibility of a unitary dimension of "subjective" or "psychological time;" the latter remains an unsupported hypothesis.

To give just one example: Eisler reported differences in duration reproduction between two ethnic groups, native Swedish and African immigrants living in Swedenmanifested in different curvatures of their response curvesand suggested "time perspective [as] a possible explanation:" in immigrants, "assimilation and separation, or loss of own culture $[. .$.$] can form the basis of a short time perspective,$ which in turn may lead to short reproductions of duration"

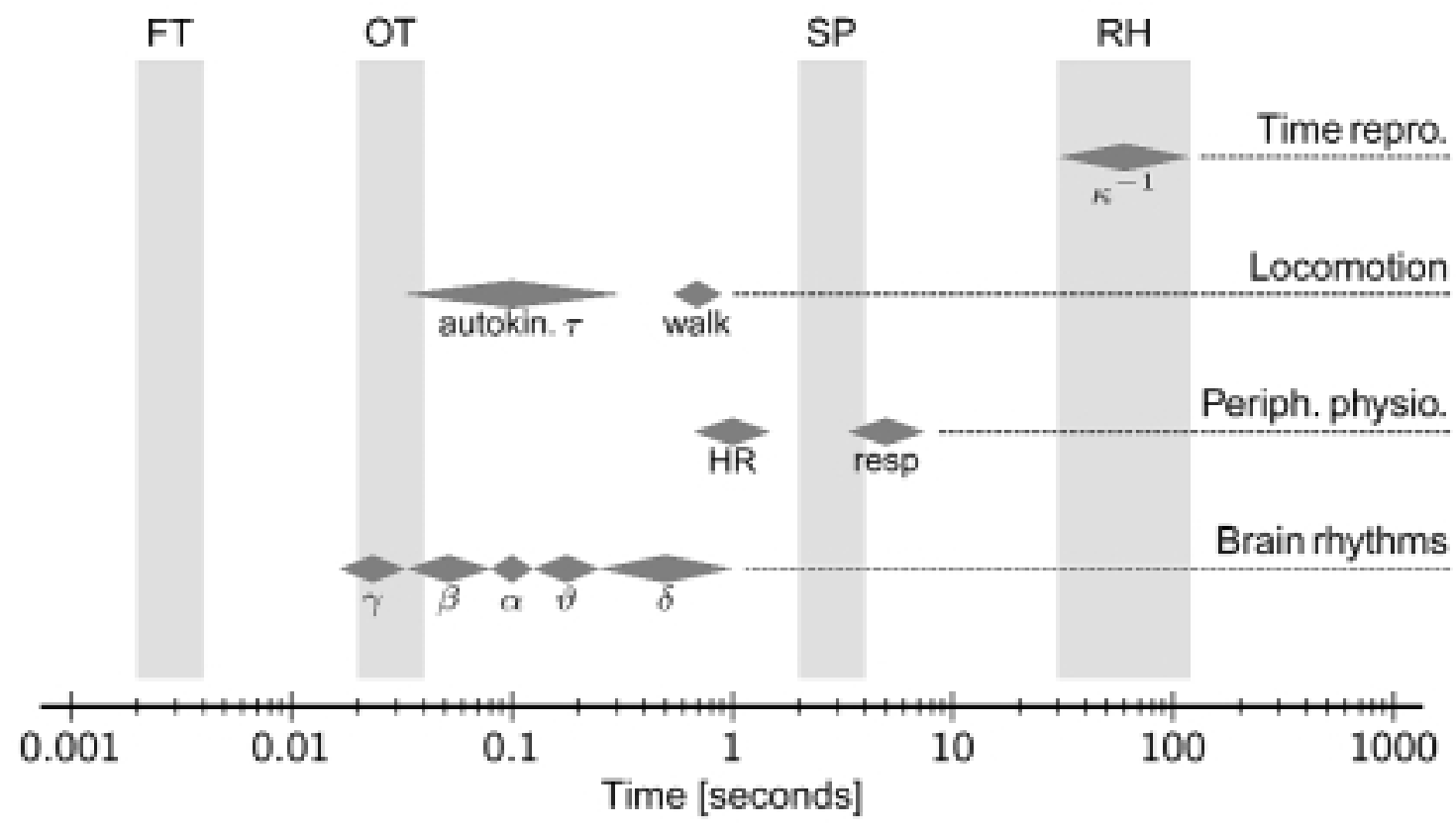

Figure 4. Characteristic times of organismic processes plotted on a logarithmic scale of physical duration. — Periodic processes: Brain oscillations (frequency bands $\gamma, \beta, \alpha, \vartheta$, and $\delta$ ); peripheral physiology (HR = heart-beat rate, resp = respiration); locomotion (walk = pacing period). - Transient processes: autokinetic times $\tau$ for various non-human species (cf. Fig. 1); relaxation times $\kappa^{-1}$ of hypothetical neural accumulators, estimated from experiments on duration reproduction. - Grey bars in the background indicate horizons of temporal experience. From left to right: fusion threshold (FT); temporal order threshold (OT); sensible present (SP); reproducibility horizon (RH) suggested as the outer horizon of duration experience.

17 We disagree about the latter point, and maintain that "the question of how these [aspects] relate to each other" is an indispensable component of "identification" of the aspects of time experience, in terms of phenomenological or psychophysical regularities. 
(Eisler, 2003, p. 14; italics ours). This interpretation assumes a causal relation between two different experiential regions, the region of one's life perspective, that is, future-oriented concepts or projects (Existenzentwürfe), with a horizon on the time scale of months or years, and the region of experienced duration, delimited by the reproducibility horizon. There is, however, no convincing evidence for a psychological or psychophysical mechanism for the alleged causal relation. ${ }^{18}$

\section{Primacy of Duration: Comments on "Time Perception" Research}

The problematic status of "psychological time" invokes serious doubts about so-called "time perception." In fact, time perception is a plain misnomer: we do not perceive time as we do perceive, say, light or sound. Woodrow, in his review of research into time perception, put this clearly when he wrote: "Time is not a thing that, like an apple, may be perceived. Stimuli and patterns of stimuli occupy physical time; and we react to such stimuli by perceptions, judgments, comparisons, estimates, etc." (Woodrow, 1951, p. 1235). In a similar vein, Pöppel plainly stated that "there is no such thing as time perception" (Pöppel, 1978, loc. cit.). ${ }^{19}$

As demonstrated above, durations immediately accessible to perceptual experience are delimited by the absolute inner and outer horizons; the phenomenon of sensible present imposes another, intermediate horizon, thus narrowing limit the region of actually perceivable durations (Figure 4). The region between this relative inner horizon and the absolute outer horizon extends from $\approx 3 \mathrm{~s}$ to $\approx 10^{2} \mathrm{~s}$. It is only within this region that we can speak, with a proper caution, about time perception-or, more properly, about perception of temporal extension of sensory events. This is in agreement with Woodrow's (1930) observation:

The subjects seemed all to be of the opinion that, if there is any experience which deserves to be called the perception of time, that such experience begins to become definite only at 1.5 to $6 \mathrm{sec}$, and continues as much the same quality of experience throughout all the longer intervals (p. 494). ${ }^{20}$

By contrast, contemporary research into time perception tends to operate in the sub-second domain (cf. Grondin, 2001), that is, beyond the horizon of duration qua temporal extension. Is this trend towards extremely short durations due to the lack of experimenters' patience? Or does it indicate a shift in the very concept of time perception? The illegitimate extension of the notion of perception beyond the limits of what is actually perceivable is methodologically questionable, and entails the danger of a gross category error. $^{21}$

A simple analogy may illustrate our point: The biological response of a human organism to electromagnetic radiation (EMR) involves many different mechanisms. For example, exposure of the skin to infra-red radiation causes thermal sensations; exposure to ultra-violet radiation may cause changes in skin pigmentation; etc. The visual sensation of light is thus merely one among many effects of EMR, confined to a relatively narrow range of wavelengths. It is physically correct to say that infra-red, ultra-violet, and visible light are various forms of EMR, differing "only" in their wavelengths-but it would be utterly wrong to subsume all of the above-mentioned effects (thermal, biochemical, etc.) under the common heading of "color perception." Psychophysical effects of EMR of different wavelengths are phenomenally different, and these differences justify the partitioning of the continuum of wavelengths to regions separated by "horizons of visibility." As we have drawn above (Section 3.3) a distinction between durations perceived and durations known, we could say that infra-red or ultra-violet light has no "perceivable color," only a "known color." Consequently, we should not confound regions of different durations only because they belong to the same abstract physical continuum "time."

\footnotetext{
18 The characteristic times, $\kappa^{-1}$, estimated by a fit of the KRF to Eisler's data, were approximately $60 \mathrm{~s}$ for the native Swedish population, and $30 \mathrm{~s}$ for the African population (Wackermann \& Ehm, 2005). It is questionable whether values of this order of magnitude could be meaningfully related to the alleged differences in "time perspective."

19 Interestingly, these views did not prevent the cited authors from publishing overviews of the topics under the traditional heading of "time perception." Cf. also footnote 4.

20 Woodrow reported experiments with the reproduction of temporal durations varied at 13 levels, in a wide range from $200 \mathrm{~ms}$ to $30 \mathrm{~s}$. Note that the geometric mean of the subjective limits for an experience of duration, as specified by Woodrow's subjects, is $3 \mathrm{~s}$ (cf. Figure 4).

21 In an informal discussion at the 20th annual meeting of the International Society for Psychophysics (Coimbra, October 2004), the author raised the question about experimenters' choice of durations of interest. An answer given by one of the leading researchers in time perception was that stimulus durations in the sub-second range "prevent subjects from counting." This anecdote makes the problem caused by the neglect of the fact of experiential horizons even more strikingly evident. Can we really speak about the experience of a duration so short that the participants do not even have time enough to utter "one, two" in their minds?
} 


\section{Spatio-Temporal Matrix of Life and the Origin of Time Horizons}

Analogy between spatial and temporal horizons. Our analyses reveal the nyo-centric ${ }^{22}$ structure of experienced time, analogous to the ego-centric structure of experienced space. The body's surface, a flexible and variable, but impenetrable boundary to one's action space, determines the innermost horizon of the primary experience of space, based upon elementary haptic/motor acts. Similarly, the temporal order threshold determines the innermost horizon of the primary experience of time, arising from elementary perceptual acts. Positions of these horizons on physical scales of length (space) and duration (time) may be approximately related by the autokinetic invariance (Section 2.3).

This analogy can be further extended: The body's actual position is always in the center ${ }^{23}$ of a space region that is "immediately attainable" by means of simple locomotor acts; the boundary of this region sets an "intermediate horizon" to the experienced space. We may see a parallel to the attainability horizon in the temporal horizon of the "subjective present" (Section 3.1), presumably resulting from "temporal integration" (Pöppel, 1978, 2004) of a stream of events into a wholeness of the momentary content of consciousness. Both intermediate horizons, the spatial and the temporal, have in common a certain flexibility and relative permeability, depending on the level of activation, vigilance, etc.

In comparing the perception of duration to the visual perception of distances, James (1890) remarked that,

[t]he former have a much narrower range; the time-sense may be called a myopic organ [...] The eye sees rods, acres, even miles, at a single glance [...] The units of duration, on the other hand, which the time-sense is able to take in at a single stroke, are groups of a few seconds (p. 611).

We would rather say that the minimum extension of the sensible present corresponds to a punctus proximus, defining an intermediate horizon within which a definite temporal order blurs and melts.

Finally, a model-based analysis of experiments with the reproduction of temporal durations reveals the ultimate outer horizon of "live experience" of duration, that is, the reproducibility horizon (Section 3.3). It is at present unclear what should correspond to this horizon in the domain of space. It would be worth exploring experimentally whether distances traveled and reproduced by active locomotion show are related by "reproduction functions" similar to those demonstrated for temporal durations. ${ }^{24}$ If this is the case, another interesting question would be whether there are invariance relations between space and time scale constants, holding at the outer horizons of spatial and temporal experience, similarly to the autokinetic invariance relation holding at the inner horizons.

Motion as the proto-phenomenon constituting spatial and temporal relations. Bergson (1888) in his Essay proclaimed the irreducibility of experienced time to the "mechanical" time of physics; in the same vein, he refuted spatial metaphors for time as inappropriate. This categorical separation of space and time seems untenable. Besides the formal analogy between abstract, mathematical, space and time (Mach, 1906, p. 100), there is also an evident analogy in the structure of experienced space and time, explained in the preceding subsection. We may consider active motion of an animate organism as the link between those two aspects of experience, the spatial and the temporal, or more properly, as the proto-phenomenal basis upon which spatial and temporal notions are being constituted.

This concept reminds us of Minkowski's (1909) famous words on "space by itself, and time by itself, vanishing into shadows and only a kind of union of the two being preserved. ${ }^{25}$ Assuming the spatio-temporal matrix of organic life as the unitary basis of space and time, we realize the need for an integrative discipline transcending classical psychophysics, a kind of "ethophysics" or "ecophysics." In this integrative discipline, observational regularities such as, for example, the above-stated autokinetic invariance may play a role similar to the "laws" in the traditional psychophysics.

The origin of spatial and temporal order in the biological proto-phenomenon of motion was latently contained in Berkeley's lucid remark: "Swiftness of ideas compared with that of motion shows the wisdom of God" (Berkeley 1707/1996, §B15). Whether we interpret the cognitive embedding of living organisms in their environments as a sign of the Creator's wisdom or as a result of biological Evolution-this may remain a matter of one's Weltanschauung or religious belief. At least, we could say that this fact reveals an aspect of the intrinsic rationality of Nature.

\footnotetext{
22 From the Greek vvv = "now" (cf. German "nun").

23 "Center" in the sense of the origin of a possible action, not the geometrical center.

24 No such data are known to the author. If experimental data of this kind exist, the author would be thankful for any reference or communication.

25 Original German quotation: "Raum für sich und Zeit für sich [sollen] völlig zu Schatten herabsinken und nur noch eine Art Union der beiden soll Selbständigkeit bewahren." (Minkowski, 1909, p. 104). However, Minkowski was referring to the consequences of a newly elaborated mathematical formalism of the relativity theory, whereas we are referring to psychophysical prerequisites of cognitive acts, out of which the concepts of physics only later arise.
} 


\section{References}

Adams, H.F. (1912). Autokinetic sensations. Psychological Monographs, 14, 1-45.

Atmanspacher, H., \& Filk, T. (2003). Discrimination and sequentialization of events in perception. In R. Buccheri, M. Saniga, \& W.M. Stuckey (Eds.), The nature of time: Geometry, physics and perception (pp. 67-75). Dordrecht: Kluwer.

Baars, B.J. (2005). Subjective experience is probably not limited to humans: The evidence from neurobiology and behaviour. Consciousness and Cognition 14, 7-21.

von Baer, K.E. (1864). Welche Auffassung der lebenden Natur ist die richtige? In K.E. von Baer (Ed.), Reden gehalten in wissenschaftlichen Versammlungen und kleinere Aufsätze vermischten Inhalts. Theil 1: Reden (pp. 237-284). St. Petersburg: Schmitzdorff.

Bergson, H. (1888). Essai sur les données immédiates de la conscience. Paris: Alcan.

Berkeley, G. (1707/1996). Philosophical commentaries. In M.R. Ayers (Ed.), George Berkeley, philosophical works, including the works on vision (pp. 305-412). London: Dent, 1996 (Original work published in 1707).

Berkeley, G. (1730/1996). Philosophical correspondance between Berkeley and Samuel Johnson. In M.R. Ayers (Ed.), George Berkeley, philosophical works, including the works on vision (pp. 413-436). London: Dent, 1996 (Original work published in 1730).

Bindra, D., \& Waksberg, H. (1956). Methods and terminology in studies of time estimation. Psychological Bulletin, 53, 155-159.

Boslough, J. (1990). The enigma of time. National Geographic, 177, 109-132.

Charnov, E.L. (1993). Life History invariants: Some explorations of symmetry in evolutionary ecology. Oxford: Oxford University Press.

Cohen, J. (1964). Psychological time. Scientific American, 211, 116-124.

Dehaene, S. (1993). Temporal oscillations in human perception. Psychological Science, 4, 264-270.

Dobbs, H.A.C. (1972). The dimensions of the sensible present. In J.T Fraser, F.C. Haber, \& G.H. Müller (Eds.), The Study of Time (pp. 274-292). Berlin: Springer.

Efron, R. (1972). The measurement of perceptual durations. In J.T. Fraser, F.C. Haber, \& G.H. Müller (Eds.), The Study of Time (pp. 207-218). Berlin: Springer.

Eisler, A.D. (2003). The human sense of time: Biological, cognitive and cultural considerations. In R. Buccheri, M, Saniga, \& W.M. Stuckey (Eds.), The Nature of time: Geometry, physics and perception (pp. 5-18). Dordrecht: Kluwer.

Eisler, H. (1975). Subjective duration and psychophysics. Psychological Review, 82, 429-450.

Fröhlich, F.W. (1923). Über die Messung der Empfindungszeit. Zeitschrift für Sinnesphysiologie, 54, 58-78.

Geissler, H.G. (1987). The temporal architecture of central information processing: Evidence for a tentative time-quantum model. Psychological Research, 49, 99-106.
Griffin, D.R., \& Speck, G.B. (2004). New evidence of animal consciousness. Animal Cognition, 7, 5-18.

Grondin, S. (2001). From physical time to the first and second moments of psychological time. Psychological Bulletin, 127, 22-44.

Havel, I.M. (2005). A structure of experienced time. In R. Buccheri, M. Saniga, \& A. Elitzur (Eds.), Endophysics, time, quantum, and the subjective (pp. 379-404). Singapore: World Scientific.

Husserl, E. (1928). Vorlesungen zur Phänomenologie des inneren Zeitbewußtseins (edited by M. Heidegger), Niemeyer: Tübingen. ( $3^{\text {rd }}$ unmodified edition, 2000.)

Husserl, E. (1976). Die Krisis der europäischen Wissenschaften und die transzendentale Phänomenologie. (Husserliana, Volume 6. Edited by W. Biemel). Hague: Nijhoff.

James, W. (1890). The principles of psychology, Volume I. New York: Holt.

Jech, R., Dušek, P., Wackermann, J., \& Vymazal, J. (2005). Cumulative blood-oxygenation level dependent signal changes support the "time accumulator" hypothesis. NeuroReport, 16, 1467-1471.

Kant, I. (1998) Kritik der reinen Vernunft. (Edited by J. von Timmermann), Hamburg. (Original work published 1787.)

Kull, K. (1999). Outlines for a post-Darwinian biology. Folia Baeriana, 7, 129-142.

Lehmann, D. (1990). Past, present and future of topographic mapping. Brain Topography, 3, 191-202.

Lehmann, D., Ozaki, H., \& Pal, I. (1987). EEG alpha map series: Brain micro-states by space-oriented adaptive segmentation. Electroencephalography and Clinical Neurophysiology, 67, 271-288.

Lehmann, H.E. (1967). Time and psychopathology. Annals of New York Academy of Sciences, 138, 798-821.

Mach, E. (1906). Space and geometry in the light of physiological, psychological, and physical inquiry. La Salle, IL: Open Court.

McMahon, T.A., \& Bonner, J.T. (1983). On size and life. New York: Scientific American Books.

Minkowski, H. (1909). Raum und Zeit. Physikalische Zeitschrift, 10, 104-111.

Morrone, M.C., Ross, J., \& Burr, D. (2005). Saccadic eye movements cause compression of time as well as space. Nature Neuroscience, 8, 950-954.

Nichols, H. (1891). The psychology of time. American Journal of Psychology, 3, 453-529. (Quoted in R.E. Ornstein, On the experience of time [pp. 16-17]. Harmondsworth, Penguin Books, 1969.)

Patterson, R. (1990). Perceptual moment models revisited. In R.A. Block (Ed.), Cognitive models of psychological time (pp. 85100). Hillsdale, NJ: Erlbaum.

Pöppel, E. (1972). Oscillations as possible basis for time perception. In J.T. Fraser, F.C. Haber, \& G.H. Müller (Eds.), The study of time (pp. 219-241). Berlin: Springer.

Pöppel, E. (1978). Time perception. In R. Held, H.W. Leibowitz, \& H.L. Teuber (Eds.), Handbook of sensory physiology, Vol. 8: Perception (pp. 713-729). Berlin: Springer. 
Pöppel, E. (1997). The brain's way to create "nowness." In H. Atmanspacher \& E. Ruhnau (Eds.), Time, temporality, now (pp. 107-120). Berlin: Springer.

Pöppel, E. (2004). Lost in time: A historical frame, elementary processing units and the 3-second window. Acta Neurobiologiae Experimentalis, 64, 295-301.

Richards, W. (1964). Time estimates measured by reproduction. Perceptual and Motor Skills, 18, 929-943.

Riemann, G.F.B. (1953/1958). Fragmente philosophischen Inhalts. In H. Weber \& R. Dedekind (Eds.), The collected works of Bernhard Riemann. New York: Dover (Originally published in 1953).

Shallice, T. (1964). The detection of change and the perceptual moment hypothesis. British Journal of Statistical Psychology, $17,113-135$.

Späti, J.P. (2005). Time perception in the context of circadian activity. Diploma thesis, University of Freiburg, Faculty of Biology.

Spiegelberg, H. (1994). The phenomenological movement. A historical introduction ( $3^{\text {rd }}$ ed.). Dordrecht: Kluwer.

Stroud, J. M. (1954). The fine structure of psychological time. In H. Quastler (Ed.), Information theory in psychology (pp. 174207). Glencoe, IL: Free Press.

Treisman, M. (1963). Temporal discrimination and the indifference interval: Implications for a model of the "internal clock." Psychological Monographs, 77 (whole number 576), 1-31.

Varela, F.J. (1999). A dimly perceived horizon: The complex meeting ground between physical and inner time. Annals of New York Academy of Sciences, 879, 143-153.

Vicario, G.B. (2003). Temporal displacement. In R. Buccheri, M. Saniga, \& W.M. Stuckey (Eds.), The nature of time: Geometry, physics and perception (pp. 53-75). Dordrecht: Kluwer.

Vierordt, K. (1868). Der Zeitsinn nach Versuchen. Tübingen: Laupp. von Steinbüchel, N., Wittmann, M., \& Szelag, E. (1999). Temporal constraints of perceiving, generating, and integrating information: Clinical indications. Restorative Neurology and Neuroscience, 14, 167-182.

von Uexküll, J. (1928). Theoretische Biologie ( $2^{\text {nd }}$ ed.). Berlin: Springer.

Wackermann, J. (2005). Experience of time passage: Phenomenology, psychophysics, and biophysical modelling. In R. Buccheri, M. Saniga, \& A. Elitzur (Eds.), Endophysics, Time, quantum, and the subjective (pp. 189-208). Singapore: World Scientific.

Wackermann, J., \& Ehm W. (2006). The dual klepsydra model of internal time representation and time reproduction. Journal of Theoretical Biology, 239, 482-493.

Wackermann, J., Ehm, W., \& Späti, J. (2003). The "klepsydra model" of internal time representation. In B. Berglund \& E. Borg (Eds.), Fechner Day 2003 (pp. 331-336). International Society for Psychophysics, Stockholm.

Wackermann, J., Späti, J., \& Ehm, W. (2005). Individual response characteristics in time reproduction and time production tasks. In J. Monahan, S. Sheffert, \& J.T. Townsend (Eds.), Fechner Day 2005 (pp. 359-364). Mt Pleasant, MI: International Society for Psychophysics.

Wittgenstein, L. (1984). Tractatus logico-philosophicus. (Werkausgabe, Band I.) Frankfurt: Suhrkamp (Original work published 1918.).

Woodrow, H. (1930). The reproduction of temporal intervals. Journal of Experimental Psychology, 13, 473-499.

Woodrow, H. (1951). Time perception. In S.S. Stevens (Ed.), Handbook of experimental psychology (pp. 1224-1236). New York: Wiley.

Received December 12, 2005

Revision received May 9, 2006 Accepted June 30, 2006 